\title{
El "diálogo" como filosofía y como praxis: la circulación de ideas alternativas sobre el pasado reciente y su recepción en la agrupación Puentes para la Legalidad
}

The "dialogue" as a philosophy and as praxis: the circulation of alternative ideas about the recent past and its reception on the political group Puentes para la Legalidad (2008-2018)

Analia Goldentul

Grupo de Estudios de Sociología Histórica de América Latina-CONICET, Argentina

agoldentul@gmail.com

Ezequiel Saferstein

Centro de Documentación e Investigación de la Cultura de Izquierdas-CONICET, Argentina

esaferstein@gmail.com

\section{ReSUMEN:}

Entre 2008 y 2018 asistimos a la gradual formación de espacios de ideas centrados en la noción de "diálogo" para intervenir en los conflictos por la memoria del pasado reciente. Estos espacios implicaron la participación de actores (gestores culturales, políticos, intelectuales y académicos) que pensaron y formularon a través de diferentes dispositivos (eventos, seminarios, libros, artículos) visiones alternativas de las políticas de DDHH impulsadas durante el kirchnerismo. En este artículo se abordará la producción y circulación de este cuerpo de ideas; para analizar en segundo término su recepción en la agrupación Puentes para la Legalidad, un colectivo que nuclea a hijos y nietos de miembros de las FF. AA. y de Seguridad procesados y condenados por crímenes de lesa humanidad y que denuncia presuntas irregularidades en los procesos judiciales.

Palabras clave: Conflictos de memoria, Diálogo, Hijos y nietos de militares.

\section{ABSTRACT:}

Between 2008 and 2018 we witness the gradual formation of spaces of ideas centered on the notion of "dialogue" to intervene in conflicts due to the memory of the recent past. These spaces involved the participation of actors (cultural managers, politicians, intellectuals and academics) who thought and formulated, through different devices (events, seminars, books, articles) alternative views of the Human Rights policies promoted during kirchnerism. In this article the production and circulation of this body of ideas will be addressed; to analyze, secondly, its reception in the association Puentes para la Legalidad, a group that brings together children and grandchildren of members of the Armed Forces and of Security prosecuted and convicted of crimes against humanity and who denounces alleged irregularities in the judicial processes.

KeYwORDs: Memory conflicts, Dialogue, Children and grandchildren of military.

\section{INTRODUCCIÓN}

Entre junio y septiembre de 2008 se desató un conflicto social y político de envergadura en torno a la modificación del sistema de retenciones móviles a la producción agropecuaria, impulsado por el gobierno de Cristina Fernández de Kirchner (2007-2011). La medida no solo provocó la reacción abroquelada de las principales entidades agropecuarias, también significó un punto de inflexión en los niveles de conflicto y polarización social. El conflicto de 2008 y sus consecuencias en el plano político aportaron condiciones de posibilidad para una redefinición de los contornos simbólicos del kirchnerismo y del antikirchnerismo, y esto liberó energías políticas basadas en el apoyo al gobierno, por un lado, y su impugnación, por el otro. Durante los meses del conflicto, amplios sectores de clases populares, de clase media y media-alta se manifestaron en las 
calles a favor y en contra de la medida, que terminó siendo vetada por el entonces vicepresidente Julio Cobos con su voto de desempate en el Senado. Así, lo que inicialmente comenzó siendo una puja por impuestos que afectaban intereses sectoriales concretos, dio lugar a un conflicto más amplio que involucró a diversos actores políticos, económicos, culturales, intelectuales y mediáticos.

En esta nueva gramática de intervenciones públicas ancladas en la exposición de sentimientos de indignación, las críticas hacia las medidas adoptadas en materia de Derechos Humanos (DDHH) tuvieron un lugar privilegiado. Si hasta entonces las agrupaciones de civiles y militares retirados se erigían como las principales voces detractoras del tratamiento estatal respecto de la dictadura (Salvi, 2012), a partir del 2008 diferentes actores, con miradas disímiles pero con posiciones privilegiadas en el campo editorial, intelectual, académico y político, reforzaron su intervención en la producción de visiones del pasado reciente, en respuesta a lo que consideraban una "memoria oficial" ${ }^{1}$ que simplificaba lo acontecido. Estas expresiones provinieron de espacios de producción cultural no marginales, que se insertan alrededor del circuito mainstream: la industria editorial, la prensa y la industria cinematográfica, así como en espacios de producción cultural más tradicionales como la academia.

La creciente visibilidad que este conjunto de posicionamientos críticos tuvo a partir del 2008 se expresó de manera heterogénea en paneles, seminarios, conferencias, libros, programas televisivos y documentales. Este crecimiento formó parte de las condiciones de posibilidad para que, años más tarde, entre 2013 y 2014, se estructuraran redes interpersonales y ámbitos de discusión de ideas centrados en la noción de diálogo, una categoría alternativa para intervenir en el campo de las memorias. Estos espacios abiertos, indefinidos y en formación, albergaron a actores, que aunque presentaban visiones críticas y propuestas "alternativas" a las políticas de DDHH implementadas durante el kirchnerismo, no pueden ser subsumidos en el arco de posiciones "negacionistas", del modo que han sido frecuentemente consideradas desde espacios cercanos a aquel oficialismo. Nuestra hipótesis es que, a la luz de las disputas políticas y simbólicas intensificadas desde 2008 entre distintos espacios en torno al gobierno kirchnerista, es posible identificar una serie de actores con posicionamientos y expresiones públicas que, si bien se encontraban aislados o en posiciones distantes entre sí, se articularon de manera potente en términos de debate público.

Trayectorias e intervenciones como las de la socióloga Claudia Hilb, del filósofo y ensayista Héctor Leis, de la dirigente política, integrante de la CONADEP y madre de un desaparecido, Graciela Fernández Meijide, del académico y director del Plan Argentina 2030, Iván Petrella, y del actual secretario de Cultura de la Nación, Pablo Avelluto, de alguna manera confluyeron como nodos de una red de actores que produjeron y articularon visiones y discursos desde posiciones de legitimidad y autoridad (moral, académica, intelectual, política). Sus producciones resuenan en ámbitos heterogéneos, y vuelven porosas esferas aparentemente distantes, como lo son el campo académico, el mundo editorial y el Estado. Una de las novedades en relación a las discusiones sobre el pasado reciente que produjo esta red de discursos, ideas y posicionamientos sobre el debate público es su recepción e interpelación a determinadas agrupaciones de civiles y militares retirados que denuncian presuntas irregularidades en los juicios de lesa humanidad. El objetivo de este trabajo es explorar la conformación de una red de ideas y actores que ubican al "diálogo" como un modo de resolver conflictos respecto del pasado reciente, en oposición a una "memoria oficial" consolidada durante el kirchnerismo. Al mismo tiempo se busca analizar su recepción en una de las agrupaciones de familiares detenidos por delitos de lesa humanidad con mayor visibilidad en los últimos años, como lo es Puentes para la Legalidad, un colectivo creado en 2008 por hijos y nietos de miembros de las FF. AA. y de Seguridad imputados, procesados y condenados por crímenes de lesa humanidad.

Pese a la vigencia que aún reviste esta trama, todavía no hay estudios académicos que exploren las redes y entrelazamientos que se producen entre estos actores. Más bien, existen valiosos aportes que hacen foco en determinadas figuras o esferas puntuales. Un trabajo que se ha dedicado a analizar los discursos de algunos de los intelectuales referidos es el reciente libro de Daniel Feierstein (2018). En sus páginas, el autor plantea que ciertas "voces progresistas", entre las que incluye a Leis y Meijide, coadyuvaron a reeditar la teoría de 
los dos demonios, ya no haciendo foco en la equiparación de responsabilidades entre "victimarios", sino en la igualación del sufrimiento entre "víctimas". Otros abordajes han estudiado de manera sistemática y profunda el repertorio discursivo de las agrupaciones de "memoria completa”, como Valentina Salvi (2012). Probablemente por la magnitud del espacio vacante que vino a suplir su trabajo, queda pendiente un análisis sobre la articulación que se produce entre estas voces y figuras del campo intelectual, académico y político. En un tercer grupo se ubican los trabajos que indagan la reedición de los conflictos por la memoria desde la asunción del gobierno de Cambiemos en diciembre de 2015, que hacen foco en los discursos de sus funcionarios (Barros, 2016) o en las notas de la prensa liberal-conservadora (Bertoia, 2016; Torras y Bertoria, 2017). Estos últimos dos trabajos, si bien son destacables, pues analizan una coyuntura que es actual, tienden a caracterizar como un todo homogéneo el complejo discursivo "del macrismo", sin distinguir las diversas posiciones y lecturas que conviven dentro de la coalición gobernante en torno al pasado reciente.

El corpus de este trabajo está compuesto por una serie de libros, documentos y artículos que forman parte de este espacio de ideas en conformación. Este corpus se complementa con observaciones no participantes en eventos académicos, políticos y presentaciones de libros en donde confluyen algunos de estos actores, $\mathrm{y}$ con una serie de entrevistas en profundidad a editores, académicos, funcionarios de gobierno, intelectuales y militantes de agrupaciones de familiares de militares, realizadas entre 2011 y 2019 por parte de los autores.

El artículo se organiza en dos apartados. En primer lugar, se analiza la producción y circulación de contenidos dialógicos, mostrando la multiplicidad de significados y actores que confluyeron en el uso de esta categoría. En el segundo apartado, se explorará la circulación que tuvo este cuerpo de ideas emergentes y su recepción por parte de espacios de militancia concretos. Para ello se realiza una aproximación a la agrupación Puentes para la Legalidad.

\section{LA PRODUCCIÓN Y CIRCULACIÓN DE VISIONES EMERGENTES}

Durante el gobierno de Néstor Kirchner (2003-2007) el tratamiento estatal de la temática dictadura formó parte de una agenda republicana de gobierno (Vommaro, 2017); esta agenda, en líneas generales, obtuvo el aval y reconocimiento de amplios sectores del ecosistema político argentino. Las críticas que hasta entonces circulaban sobre la recuperación de ex centros clandestinos de detención o sobre la reapertura de los juicios por crímenes de lesa humanidad ocupaban un lugar marginal y a menudo eran enunciadas por actores -individuales o colectivos- con escasa legitimidad en el espacio público para generar principios de adhesión en audiencias masivas. Un ejemplo de estas "voces marginales" lo constituyeron aquellos sectores de civiles y militares retirados que desde fines de la década del noventa militaban la consigna de practicar una "memoria completa" (Salvi, 2012), por medio de libros y revistas vinculados al ámbito militar o policial.

Como señalamos en la introducción, el conflicto entre el gobierno y las principales entidades agropecuarias, entre junio y septiembre de 2008, significó un punto de clivaje a nivel social y político. La polarización que trajo aparejada este hecho tuvo repercusión en el campo de las memorias, donde afloraron miradas críticas sobre la visión "parcial” que el Estado institucionalizaba a través de sus diferentes agencias y ministerios.

La proliferación de libros best sellers que se propusieron revisitar la violencia armada fue uno de los primeros indicadores de este despertar crítico. Aunque se trató de una tendencia previamente existente, la publicación seriada de libros políticos sobre los setenta reconoció un impulso a partir del 2008 (Saferstein, 2016). Pablo Avelluto, director editorial de Random House - Sudamericana entre 2005 y 2012 y ministro de Cultura de la Nación a partir de diciembre de 2015, fue un actor clave en la identificación y creación de una oferta de libros sobre el pasado reciente. Desde esa posición estratégica, lanzó autores que publicaban en editoriales de derecha de escasa circulación, como Juan Bautista Yofre (Edivern) y otros que no habían publicado, como Ceferino Reato, y los posicionó como “referentes” de la temática desde el periodismo (Saferstein, 2017). 
En el campo académico también emergieron trabajos críticos del tratamiento estatal del pasado reciente (Vezzetti, 2009; Carnovale, 2011; Leis, 2013; Hilb, 2013), precedidos en 2004 por la polémica que desató la carta del poeta y ensayista Oscar del Barco en la revista cordobesa La Intemperie, en la que cuestionaba el accionar de las organizaciones respecto de sus propios militantes. Varios de estos autores formularon, además, visiones críticas del tratamiento jurídico de los crímenes cometidos (Hilb, 2013; Hilb, 2014; Salazar, 2014), ${ }^{2}$ en las que apareció cuestionada la predominancia de una vocación punitivista de los agentes de represión estatal por sobre otros dispositivos enfocados en la obtención de verdades socialmente esperadas, tal como el que se implementó en Sudáfrica con la Comisión sobre la Verdad y la Reconciliación entre 1995 y 1998. Esta posición apareció claramente objetivada en el libro Usos del pasado (2013), de la socióloga e investigadora del Consejo Nacional de Investigaciones Científicas y Técnicas (CONICET), Claudia Hilb. Al año siguiente la autora compiló, junto a Philippe-Joseph Salazar y Lucas Martín, el libro Lesa Humanidad. Argentina y Sudáfrica: reflexiones después del Mal (2014), en el que se retoman aspectos de la Comisión para la Verdad y la Reconciliación de Sudáfrica considerados fructíferos para pensar el caso argentino.

Por fuera del ámbito académico y en línea con una circulación y difusión de tipo mainstream, a partir de 2014, la conformación previa de una literatura crítica de las políticas de DDHH implementadas durante el kirchnerismo dio cauce a la producción y circulación de productos culturales dentro y fuera del mercado editorial. En este esquema, Avelluto tuvo un rol articulador clave; impulsó redes interpersonales entre actores, que, desde distintos campos de intervención, presentaban visiones disruptivas del pasado reciente. Su pertenencia al Club Político Argentino, ${ }^{3}$ su posición destacada en el campo editorial y su acercamiento a la gestión de gobierno de la Ciudad de Buenos Aires en 2013 lo ubicaron además como "conector entre el PRO y ciertas fracciones del mundo intelectual” (Saferstein, 2017). La proliferación de estos vínculos se materializó prontamente en libros, notas periodísticas, discursos públicos, eventos y conferencias que -sin comulgar con el revisionismo practicado por las organizaciones de "memoria completa" y luego de adoptar como punto de partida la importancia ética del "contrato social” del Nunca Más (1984)- buscaron complejizar algunas premisas historiográficas, como así también pensar dispositivos alternativos o complementarios a la vía judicial para tramitar la "tragedia" de los setenta.

Como hemos anticipado en avances previos (Goldentul y Saferstein, 2018; 2019), la apelación a la noción de diálogo fue el eje vertebrador entre producciones muy distintas entre sí.

Un momento bautismal, que le dio mayor cohesión e identidad a estos espacios de ideas y redes interpersonales, fue el lanzamiento en abril de 2014 del documental El diálogo: El encuentro que cambió nuestra visión sobre la década del 70. Producido por Avelluto, Carolina Azzi y Pablo Racioppi, un año después lanzado como libro bajo el sello de Sudamericana, este consistió en una conversación entre Héctor Leis ex integrante de Montoneros, doctor en filosofía y ensayista - y Graciela Fernández Meijide -integrante de la CONADEP, miembro de la Asamblea Permanente de Derechos Humanos (APDH), ex dirigente del Frepaso y madre de un desaparecido-. Los diálogos entre dos personas que "vivieron los setenta" y que, por lo tanto, cuentan con autoridad para pronunciarse al respecto, buscaron visibilizar otra narrativa y cronología del pasado reciente, enfatizando los años 1973-1976 como una etapa de recrudecimiento de la violencia y señalando la responsabilidad de los actores armados en el desencadenamiento del golpe. Pero, ante todo, el producto fue valorado como rupturista por su formato: un diálogo "plural", con silencios y ocurrencias de los protagonistas que expresaban miradas y aprendizajes del pasado reciente en un tono parsimonioso que se mantuvo de principio a fin.

El mercado editorial constituyó, nuevamente, un espacio predilecto para observar este mayor hincapié en la noción de diálogo. En Que se metan todos (2015), del secretario de Integración Federal y Cooperación Internacional del Ministerio de Cultura (2015-2017) -y, desde 2017, director del Plan Argentina 2030-, Iván Petrella, se recuperó aquel documental para dar cuenta de una verdad más "plural" que solo podría producirse en un contexto de diálogo y de reconocimiento del otro. ${ }^{4}$ También recomendaba atender a otras experiencias, como la ya referida Comisión de Verdad y Reconciliación en Sudáfrica, citando y 
apropiándose de algunos de los argumentos esgrimidos por Claudia Hilb, principal referente académica argentina que recupera las virtudes de ese modelo. La noción de diálogo también atravesó el libro de Carolina Arenes y Astrid Pikielny, Hijos de los 70: Historias de la generación que heredó la tragedia argentina (Sudamericana, 2016). El libro presenta relatos de hijos de represores y de militantes de organizaciones armadas con el objetivo, según explicaron las autoras en el prólogo, de "imaginar un diálogo posible", "un diálogo abierto" (2016, p. 11). Posteriormente, la experiencia de la publicación fue retomada por Hilb en ¿Por qué no pasan los setenta? (2018), y valorada por su contribución a la formación de una memoria "plural" y "contradictoria", que recupera "voces silenciadas".

Este conjunto de citas cruzadas (Petrella citando a Hilb, Hilb referenciando a Arenes y Pikielny y estas últimas agradeciéndole a Pablo Avelluto el estímulo) revelan un espacio interdiscursivo, una red de vínculos conformada por autores y lectores que portan diversas trayectorias, experiencias y miradas del pasado reciente, donde los "vínculos en el papel" pueden traducirse, de manera efectiva o potencial, en la participación de espacios y ámbitos de producción cultural e intelectual.

Si bien el uso de la categoría de diálogo no es nuevo ni privativo de estas últimas intervenciones, ${ }^{5}$ en estas páginas sugerimos una renovación en sus usos y significados. En primer lugar, las apelaciones actuales del diálogo, con sus diferencias y matices, ${ }^{6}$ secularizan el léxico reconciliatorio al despojarlo de valores y cargas religiosas. $^{7}$

Por otra parte, algunos actores y espacios que comulgan con las ideas dialógicas son pragmáticos en su intervención, y entienden que las luchas por los sentidos del pasado reciente pueden resolverse o gestionarse mediante un entendimiento entre "las partes". Este entendimiento se observa como posibilidad ante la existencia de posiciones encarnadas por sujetos "racionales", alejados de extremismos, en línea con una concepción decimonónica y liberal del diálogo (Mouffe, 2012). Delimitado, entonces, a aquellas personas que poseen la virtud de la "razón" y la capacidad de la escucha, el "diálogo" que proponen estos actores interpela y convoca a quienes comparten previamente un conjunto de valores y visiones comunes valoradas como racionales y medidas (Souroujon, 2018), frente a otras posiciones que son juzgadas de obtusas, cerradas e irracionales (Goldentul y Saferstein, 2018).

Este elemento puede vislumbrarse en el documental. Aunque fue referido y elogiado como un encuentro de dos personas que piensan "muy distinto" (Avelluto, 2013), sus protagonistas presentaban más acuerdos que divergencias sobre el pasado reciente y el presente político de ese momento. En efecto, Leis y Meijide coincidían en su rechazo a la visión heroica de la militancia armada, objetaban la posición de los organismos de DDHH durante el kirchnerismo sin realizar distinciones entre las diferentes entidades y criticaban el tratamiento estatal que tuvo la temática desde 2003 en adelante.

Desde esta perspectiva, los contornos del "otro" con el que se conversa son difusos. Así como las ideas reconciliatorias en general tendieron a identificar a víctimas y victimarios como los protagonistas de un pacto reconciliatorio, en la matriz que se presenta en este trabajo el repertorio de figuras que pueden encauzar el diálogo es más amplio. Los interlocutores pueden ser militares o policías que participaron del terrorismo de Estado, junto a miembros de una organización armada, o entre familiares de un desaparecido y de un represor. En El Diálogo, Meijide - madre de un desaparecido- ocupa la figura de la víctima y no conversa con un integrante de las FF. AA., sino con un miembro de Montoneros arrepentido de su pasado. Leis, en términos relacionales, representa la figura de "perpetrador", responsable y partícipe de la violencia armada. Por su parte, en Hijos de los setenta, las autoras apuntan hacia el horizonte de lograr que sean los descendientes de los protagonistas los que entablen un diálogo. El libro de Arenes y Pikielny retrata encuentros que no adoptan el tradicional formato "cara a cara" (cada capítulo del libro se enfoca en la reconstrucción de una historia individual, de manera que los diálogos se dan "entre textos"). Tampoco se ciñen al intercambio entre dos personas, sino que pueden implicar una multiplicidad de actores (el libro contiene veintitrés relatos).

Aunque estos espacios de ideas y actores no se hallan necesariamente cohesionados, y las nociones de diálogo y reconciliación que emanan de los libros, artículos y conferencias presentan diferencias, existieron 
ciertos correlatos institucionales desde el Ministerio de Cultura de la Nación (2015-2017). El programa Diálogos globales, ${ }^{8}$ en octubre de 2016, y el encuentro "Ideas. Pensemos juntos el futuro", 9 en septiembre de 2017, fueron el marco para la circulación entre distintos actores como Norma Morandini -periodista, otrora senadora, familiar de dos desaparecidos y Directora del Observatorio de DDHH del Senado desde 2015-, Aníbal Guevara, referente de la agrupación Puentes para la Legalidad e hijo de un militar condenado por la represión ilegal en la provincia de Mendoza, y Claudia Hilb, que en sucesivas ocasiones fue invitada por Petrella a participar como expositora pero siempre declinó la invitación (Claudia Hilb, 31/10/2018). El formato elíptico de estos eventos merece ser destacado, en tanto se enfocaron en discutir formas alternativas de "resolución de conflictos" de otros países, como Sudáfrica o Colombia, y se evitó hablar de manera directa sobre el caso local, aunque la comparación aparecía de manera potencial (Goldentul y Saferstein, 2018). De este modo, la cartera que dirige Avelluto puede ser pensada como un espacio estratégico para articular actores y visiones cercanas a una idea particular de diálogo, poniendo de relevancia la importancia que le asigna un sector del gobierno de Cambiemos al plano cultural para intervenir en el conflictivo campo de las memorias. Veremos a continuación que la noción de diálogo no debe ser analizada tanto por su densidad filosófica y política, sino fundamentalmente como categoría nativa de los propios actores, que mediante su enunciación y creencia construyen redes, lazos y sensibilidades.

\section{La recepción del dialoguismo en la agrupación Puentes para la legalidad}

La gradual formación de una red de actores e ideas centrada en la noción de diálogo no solo se plasmó en libros y en un documental; también se materializó en vínculos, redes interpersonales, encuentros, amistades y afectos que transformaron intereses y objetivos en valores deseables y compartidos. Desde 2014, Fernández Meijide participó de la promoción de El Diálogo, en eventos y ciudades del país que acercaron los contenidos "dialógicos" a distintas audiencias (Goldentul y Saferstein, 2018). Un evento que interesa destacar en particular fue "Bicentenario y Cultura del Encuentro", que tuvo lugar en junio de 2015 en el Museo de la Ciudad. El mismo contó con "mesas de diálogo" dedicadas al debate de problemas relativos al pasado y presente argentino. Uno de esos paneles estuvo integrado por Fernández Meijide y el ya referido Aníbal Guevara, vocero de Puentes para la Legalidad. De manera similar a otros eventos en los que había asistido la ex integrante de la CONADEP, la mesa reunía dos protagonistas presentados como eventualmente opuestos, pero que podían dialogar entre sí. Ambos relatos dieron cuenta de recorridos exitosos de superación del dolor y la bronca (Fioravanti, 2018), y fueron expuestos como ejemplos a seguir por el pblico presente, que en su mayoría estaba compuesto por familiares de personas detenidas por crímenes de lesa humanidad. Precisamente, ante la inquietud de una asistente que le había preguntado a Guevara cómo se sostenía para sobrellevar la "arbitrariedad" de los procesos judiciales, este sealó que controlar la bronca y el resentimiento había sido y era "un laburo" constante, que a él lo había ayudado leer libros que tematizaban sobre la violencia de la década del setenta desde posiciones distintas:

Yo no soy docente pero puedo decir cómo yo enfrenté el pasado cuando me vi envuelto en esta situación y fue leer todo lo que llegaba a mis manos. Y tratar de mechar, porque si me ponía a leer todo lo que era antimilitar me iba a hacer mal, y si leía todo lo que era antiguerrilla también me iba a hacer mal. Me iba a llenar de una bronca y de un resentimiento que no me sumaban, no me ayudaban a construir (Aníbal Guevara, conferencia en el Museo de la Ciudad, 5/6/2015).

La literatura a la que se refirió puede dividirse en tres grupos. En primer lugar, los best sellers publicados a partir del 2008, que apuntaron a revisar los hechos de la última dictadura desde nuevos/viejos argumentos, entre ellos: Volver a Matar (2009) y ElEscarmiento (2010) de Juan Bautista Yofre, y Disposición Final (2012) de Ceferino Reato, publicados por Sudamericana durante la gestión de Avelluto. Un segundo grupo abarca aquella literatura considerada por Guevara como propia de referentes del “otro lado": La Voluntad (2006), de Eduardo Anguita y Martín Caparrós, y Un testamento de los años '70, de Héctor Leis. En un tercer grupo 
se ubican libros académicos, como Usos del Pasado (2013), de Claudia Hilb, y Lesa Humanidad (2014), una selección de artículos compilados por Claudia Hilb, Lucas Martin y Philippe-Joseph Salazar.

El consumo de estas obras, que en la visión de Guevara eran representativas de “todos los bandos”, revela aspectos de la recepción y circulación que tuvieron los libros críticos de la "memoria oficial” del kirchnerismo. Estudios de recepción vinculados a la historia intelectual permiten indagar cómo las lecturas de determinados textos constituyen operaciones activas que están sujetas a interpretaciones, prácticas y discusiones que dependen de quiénes realizan esas apropiaciones, quiénes son los autores de los textos a interpretar, quiénes los publican, cómo y a través de qué redes circulan, entre otras dimensiones (Tarcus, 2013). Más allá de que las intenciones de los autores de esta literatura, sus públicos esperados, sus interlocutores elegidos explícita o implícitamente coincidan o no con su efectiva circulación, Guevara da cuenta de un espacio de autores que lo interpelan. Las lecturas de la literatura sobre los años setenta pusieron de relieve la importancia por él asignada a la formación intelectual y militante. Así fue componiendo las piezas de su posición política que hoy coincide, en gran medida, con la posición pública de Puentes para la Legalidad.

Este colectivo fue creado en 2008 por parte de hijos y nietos de agentes procesados o condenados que se conocieron entre sí en las visitas a la Unidad Penitenciaria No 34 de Campo de Mayo. Con el objetivo, más pragmático que ideológico, de "hacer algo" respecto de presuntas "irregularidades" que afectan los procesos judiciales de sus familiares, eligieron llamarse inicialmente Hijos y Nietos de Presos Políticos (HNPP). Desde su surgimiento, el colectivo fue creciendo a la par del avance de los juicios y del número de militares y policías detenidos. La mayoría de sus integrantes osciló entre los 25 y 35 años, lo cual implicó una renovación generacional dentro del campo de agrupaciones de civiles y militares retirados.

La creación del grupo no puede disociarse de la mayor conflictividad social que se vivió a partir de 2008, la cual derivó en un incremento en los niveles de politización social en el segmento más joven de la sociedad. La circulación de narrativas que comenzaron a hacer énfasis en "el regreso de los jóvenes a la política" y la implementación de políticas estatales que reforzaban el vínculo entre juventud y política (Vázquez, 2013) repercutieron en los integrantes del grupo, quienes hicieron de la condición juvenil su marca identitaria. Precisamente, en la primera carta de presentación del colectivo se definieron como un:

grupo de argentinos que compartimos el dolor de ver a nuestros padres y abuelos presos por persecución política. Pero tenemos en común algo más que la misma adversidad enfrentada, somos jóvenes y queremos ser protagonistas de la Argentina del futuro (...) (Carta de Presentación, Blog de HNPP, 2/12/2009. El énfasis es nuestro).

En sus comienzos, sin embargo, adoptaron un lenguaje confrontativo que era similar al de otras agrupaciones que defienden los intereses de agentes de la dictadura. Sus integrantes participaban en actos organizados por organizaciones de memoria completa, en los que se homenajeaba a los "muertos por la subversión" en la Plaza San Martín, y mantenían cercanía con algunos colectivos específicos, como con la Asociación de Familiares y Amigos de Presos Políticos de Argentina (AFyAPPA), dirigida por Cecilia Pando (Goldentul, 2018).

Sería en septiembre de 2011, durante una intervención contra el juez supremo Ricardo Lorenzetti en la que presentaba su libro Derechos Humanos: Justicia y reparación en la Facultad de Derecho de la UBA, cuando se vieron obligados a buscar una comunicación más templada. Momentos previos al inicio del evento, alrededor de quince familiares de militares lograron ingresar al auditorio de la Facultad de Derecho y, tras un tiempo de espera, interrumpieron la presentación para denunciar en voz alta la "violación" de derechos humanos contra sus padres y abuelos. El episodio tuvo eco en más de diez portales de noticias, ${ }^{10}$ algunos de los cuales llegaron a reproducir los detalles del altercado:

"No se respetan los Derechos Humanos, mentiroso, hijos de puta", gritaron los manifestantes cuando Lorenzetti comenzaba a presentar su reciente libro sobre Derechos Humanos. Ante esto, Lorenzetti atinó a decir: "Chicos, tranquilícense y vamos a hablar después" (Urgente 24, 28/09/2011). 
La desaprobación pública y mediática que tuvo el escrache motorizó debates internos orientados a repensar las formas de intervención. Aprender a disciplinar y doblegar las emociones en el espacio público implicó un esfuerzo de magnitud en el plano individual y colectivo. Junto con el acompañamiento de Milena, ${ }^{11}$ una integrante de 34 años, abogada e hija de un policía condenado por su participación en la represión ilegal de la provincia de Tucumán, las reuniones semanales de la agrupación se transformaron en escenarios de fuertes discusiones sobre la orientación que debían asumir.

De manera progresiva, los integrantes de HNPP establecieron criterios de diferenciación respecto de sus familiares. Como señaló Alejandra - una integrante de 32 años cuyo padre, militar del Ejército (r), fue condenado en 2010-, los integrantes del grupo, a diferencia de sus familiares, no habían sido "testigos" de esa época; no habían "vivido el conflicto desde adentro" (Alejandra, 13/12/2016). La falta de una vivencia directa de la violencia de los setenta, como un argumento que muchas veces los desautorizó para expresar sus opiniones dentro del campo de agrupaciones de civiles y militares retirados, comenzó a operar de manera productiva: si no habían vivido esa época no tenían sustento para pronunciarse al respecto ni para cumplir con las expectativas que a veces recaían sobre ellos en cuanto al uso de la palabra. ${ }^{12}$

En lugar de intervenir en los conflictos por la memoria, decidieron limitar las denuncias a las presuntas “irregularidades" de los procesos judiciales. ${ }^{13}$ Las demandas fueron articuladas y verbalizadas a través de un lenguaje humanitario que evitaba contradecir aquellas verdades socialmente aceptadas del pasado reciente: no negaron la existencia de los desaparecidos como tampoco las responsabilidades de aquellos agentes que cometieron crímenes (Goldentul, 2018). Según dicen, el lema de la agrupación -No hay Justicia sin legalidad-parte de un entendimiento hacia la demanda social de los juicios. La mayoría de los entrevistados afirmó no oponerse a la Justicia como ámbito para dirimir los crímenes cometidos en dictadura. "Ellos tienen derecho a saber qué le pasó a sus familiares y que se haga justicia”, afirmó Milena, mostrando empatía hacia las demandas de los familiares de desaparecidos. Mediante la apelación a la noción de legalidad comenzaron a objetar, ya no el hecho de que sus familiares fueran sometidos a un juicio, sino las vías o formas procedimentales adoptadas por los jueces y fiscales para dictaminar las condenas:

Queremos que estos juicios sean un ejemplo de cómo las cosas pueden hacerse bien, que el día de mañana ningún ciudadano sea sometido a juicio con las reglas cambiadas o aplicadas según la conveniencia del poder de turno (Blog de HNPP, 6/03/2014. El énfasis es nuestro).

La búsqueda por alcanzar una comunicación más “racional” y menos ideológica (Fioravanti, 2018), según expresó Mariano, un integrante de 52 años que es reconocido internamente como uno de los impulsores del grupo (Mariano,12/03/2019), comenzó a contrastar con la agresividad lingüística con que usualmente se manifestaban algunos familiares y miembros de agrupaciones cercanas. Los desencuentros o rispideces que tuvieron con miembros de otras agrupaciones fueron mencionados de manera recurrente por los miembros de HNPP para delimitar fronteras y subrayar un estilo propio. En palabras de Gisela, una integrante de 34 años, cuyo padre fue condenado por su participación en la represión ilegal de la provincia de Formosa:

$\mathrm{Al}$ principio cuando nosotros salimos con este discurso no fue muy bien recibido por las esposas o por algunos militares. Estaban todo el tiempo hablando del pasado: "que no, que perdieron y blabla" (....). Porque para ellos que lo vivieron era como que los juicios casi no se podían hacer, directamente. Incluso hay algunos hijos que tampoco, hijos más grandes que vivieron esa época (Gisela, 13/12/2016. El énfasis es nuestro).

En la búsqueda por ampliar los horizontes de intervención pública, tensaron vínculos y relaciones no solo con otros colectivos sino también en el interior del propio grupo. Aquellos hijos que "vivieron" los setenta y que no estaban dispuestos a "resignar banderas" abandonaron el grupo.

Esta reconfiguración de relaciones existentes se dio en simultáneo con la generación de nuevos vínculos. La intervención contra Lorenzetti en la Facultad de Derecho significó un punto de clivaje en otro aspecto. No solo los obligó a repensarse como colectivo y a desarrollar nuevas formas de intervención, también les permitió darse a conocer públicamente aunque fuera en el contexto de un escrache. Luego de ser expulsados 
del aula magna, algunos de ellos conocieron a Pablo Avelluto, quien había asistido a la presentación del libro como editor. Guevara dijo recordar bien ese momento:

\begin{abstract}
Dábamos vuelta por todos lados [de la facultad] a ver a quién podíamos enganchar...vemos a Pérez Esquivel hablando con no sé quién y en eso Avelluto le da la tarjeta a mi hermana y nos dice "llámenme". Y cuando nos juntamos después de varias semanas de rastrearlo, de llamarlo, me dice: "yo vi que lo que le estaban pidiendo al presidente de la Corte es que los recibiera porque había cosas que se hacen mal y yo considero que en estos juicios nada debiera hacerse mal, justamente por lo que se está juzgando. Y vi que además eran pibes normales, entonces me asombré de mis propios prejuicios (...) Me asombré de estar asombrándome de que fuesen normales. Eran pibes con jeans". Yo -dice Guevara- no sé qué esperaba de hijos de militares. Imagino que él esperaba una cosa más acartonada (Aníbal Guevara, 18/10/2016)
\end{abstract}

Poco tiempo después, el entonces director editorial de Sudamericana entrevistó a los hermanos de Guevara con la idea de hacer un libro. El proyecto no prosperó porque, según le explicó al vocero de HNPP, el tema "lo afectó emocionalmente". Pese a ello, ambos construyeron una relación de entendimiento sobre la base de esporádicos encuentros. Aquel contacto con la agrupación fue el primero de una serie de vínculos que ayudaron a los integrantes de HNPP a insertarse en otros espacios de discusión donde, a partir de 2013, comenzaría a aflorar la noción de diálogo. Esa categoría sería utilizada por Cambiemos como leitmotiv de su campaña electoral de 2015 y luego incorporada al discurso gubernamental como emblema de la nueva gestión (Souroujon, 2018).

Aunque el "diálogo" como paradigma emergente para tratar los crímenes de Estado no se reflejó inmediata ni unilateralmente en las prácticas políticas y discursivas del colectivo, algunos de sus integrantes comenzaron a interactuar con figuras militantes o afines a esta idea. ${ }^{14}$ Fue en la presentación de El Diálogo en el Buenos Aires Festival Internacional de Cine Independiente (BAFICI), el 9 abril de 2014, cuando Guevara conoció a Fernández Meijide. ${ }^{15}$ Un año después, en la mesa compartida en el Museo de la Ciudad a la que nos referimos al principio de este apartado, el vocero de HNPP rememoró con palabras afectivas el momento en que conoció a la ex integrante de la CONADEP:

en la presentación del documental, Pablo [Racioppi] nos presentó a Graciela, que inmediatamente nos invitó a su casa... y nos alojó en algún punto. Para nosotros que estamos acostumbrados a tanto prejuicio, el hecho de que ella, con toda su historia, nos estuviera escuchando tuvo un significado impresionante. Y nos dijo "ustedes tienen que hacer como hicimos nosotros" [en alusión a las tareas hechas por la CONADEP]. Nos habló con una empatía enorme. No había mucha gente que nos dijera "nosotros". Es una palabra muy muy fuerte (Aníbal Guevara, Conferencia en el Museo de la Ciudad, 5/06/2015)

Aníbal y otros integrantes también participaron como oyentes de los ya referidos Diálogos Globales e IDEAS, en 2016 y 2017 respectivamente, donde pudieron conocer e interactuar con funcionarios del Ministerio de Cultura, como Iván Petrella, quien reconoce el carácter innovador de esta agrupación:

Yo después del evento en la Casa Rosada, en IDEAS también, hablé con Aníbal, una vez hablé con él por teléfono pero nunca me junté con el grupo. Tal vez es algo para retomar. Está en todos lados. Él sí, la verdad me parece una iniciativa inteligente la de él (Iván Petrella, 25/04/2018).

La recepción y ampliación de relaciones, vínculos y saberes se reflejaron, paulatinamente, en el discurso colectivo de la agrupación. En particular, la mirada de Meijide sobre la reconciliación y el perdón le permitió a Guevara y al resto de los integrantes de la agrupación matizar aquellas ideas. En reiteradas oportunidades la dirigente había sostenido que ella no podía perdonar ni reconciliarse con las personas que desaparecieron a su hijo, pero que estaba dispuesta al encuentro y diálogo con el otro. Si la idea de reconciliación tenía una presencia firme en el complejo discursivo de HNNP, en octubre de 2015 Aníbal ya anticipaba un cambio de registro: esa idea, la de reconciliación, le comenzaba a resultar muy "pretensiosa” (Aníbal Guevara, 15/10/2015). En su mirada, la agrupación ya no tenía objetivos reconciliatorios, sino que se militaba por el "encuentro" y "diálogo" con el otro.

Además de los intercambios con Fernández Meijide, la agrupación se retroalimentó de lecturas, saberes y conversaciones con referentes consagrados del campo intelectual y académico que participaban -de diversas 
formas y con intensidad variable- en este espacio de ideas, prácticas y voluntades. El "dialoguismo" articula a voces autorizadas que poseen credenciales educativas (estudios de posgrado en universidades nacionales o extranjeras) y obras publicadas por editoriales de prestigio, con amplia circulación en espacios educativos y políticos diversos. Algunos pueden incluso certificar su acervo intelectual a partir de experiencias de vida entramadas en la violencia de los años setenta, como son los casos de Leis y de Hilb. La vinculación con intelectuales, en tanto portadores de visiones del mundo validadas en un conocimiento "racional", se ató a la búsqueda de los referentes de HNPP - entre ellos, Aníbal y Milena- de intervenir con argumentos medidos y equilibrados, en oposición al "fanatismo" y la irascibilidad con que se manifiestan otras agrupaciones entrampadas en sentimientos de "odio" (Fioravanti, 2018). Entre las figuras del campo cultural y académico con las que HNPP entabló conversación se destacan Alejandro Katz, Santiago Kovadloff y Luis Alberto Romero, tres socios del Club Político Argentino, junto a Meijide y Avelluto. También tuvieron un lugar destacado los intercambios de Aníbal con Hugo Vezzetti y Claudia Hilb. Estos acercamientos entre algunos integrantes de HNPP con personalidades reconocidas del campo intelectual fueron particularmente valorizados en la concepción de Aníbal, en comparación con otras figuras:

\footnotetext{
Necesitamos a los periodistas para retransmitir nuestro mensaje. Pero el periodismo es un núcleo absolutamente cerrado a nosotros, por prejuicio y temor. Porque [nos dicen] "vos sos procesista", "vos le das lugar a la derecha", "vos le hacés el juego a la derecha". Entonces, ¿quién influye a los politicos y periodistas? Los intelectuales. Y además, como no son tan conocidos no tienen tanta gente atrás yéndolos a molestar por miles de temas. Y además es gente curiosa, son más permeables a recibirnos y escuchar. Que pase nuestro discurso es otra cosa, pero en principio conocernos y escucharnos (...) De todos los que vamos leyendo cosas interesantes los contactamos para poder hablar (...) Además la devolución siempre te enriquece infinitamente, ¿entendés? (Aníbal Guevara, 8/08/2015. El énfasis es nuestro).
}

Con todo, la búsqueda de referencias intelectuales no implicó necesariamente la construcción de vínculos de reciprocidad librados de tensiones o divergencias. La rispidez que laminó algunos de estos intercambios se observó, por ejemplo, en la que fue una de las primeras conversaciones que enriqueció a la agrupación: la entablada con Hugo Vezzetti, profesor de la Universidad de Buenos Aires (UBA), investigador del CONICET y referencia ineludible en el campo de estudios sobre el pasado reciente. Fueron contactados a través del historiador Luis Alberto Romero, profesor de la UBA. Aunque en un primer momento Vezzetti se negó a conversar con los integrantes de HNPP, luego les concedió una reunión que Guevara recuerda hasta hoy como áspera: "Vezzetti nos dijo 'yo los recibí porque me lo pidió Luis Alberto, si no, no los recibía '” (Entrevista a Aníbal, 18/10/2016).

En el cambio de nombre de Hijos y Nietos de Presos Políticos a Puentes para la Legalidad incidió sobremanera el cuestionamiento que Vezzetti, autor de Pasado y Presente, les hizo sobre la utilización de la categoría de presos políticos para señalar la condición legal de sus familiares. Hasta ese entonces, los miembros del grupo habían justificado su uso en virtud de la "utilización política", que, según entendían, la dirigencia kirchnerista hacía de los juicios (Blog de HNPP, 1/12/2012). Este uso resultaba disonante respecto del sentido convencional del término, que alude a personas que han sido privadas de su libertad en virtud de sus convicciones y actividades políticas. En el argumento que ofrecían, el componente político era connotado de manera negativa, y adjudicado no a los detenidos, sino a los ex funcionarios de gobierno. Frente a estos problemas definicionales, Aníbal señaló, en la mesa que compartió con Meijide en el Museo de la Ciudad, que la charla con Vezzetti los “ayudó a entender” y los “interpeló con respecto a los derechos humanos”. En lugar de apelar a razones políticas para explicar el porqué de las detenciones, por sugerencia de Vezzetti, debían apuntar a realzar la dimensión humana de los detenidos:

Nos dijo que los derechos humanos se ponen en juego cuando se trata de alguien que es diferente a nosotros. Porque es muy fácil defender los derechos humanos de alguien que es como nosotros; estos se ponen en juego cuando es hacia otro (Aníbal Guevara, Conferencia en el Museo de la Ciudad, 5/06/2015). 
La relación entablada con Claudia Hilb -UBA, CONICET, con un pasado militante en las Fuerzas Argentinas de Liberación (FAL $)^{16}$ - presentó un nivel de consolidación mayor que el vínculo que Aníbal tuvo con los otros intelectuales mencionados. El mutuo respeto ${ }^{17}$ y la consideración que tiene Hilb del vocero de HNPP como una figura "excepcional” entre aquellos que denuncian irregularidades en los juicios (Hilb, 31/10/2018) no implicó, sin embargo, que la autora de Usos del pasado comulgue con las lecturas $\mathrm{y}$ apropiaciones que pueden hacer esta u otras agrupaciones de familiares de militares de sus obras, ni que adopte como horizonte de escritura a dichos actores:

Yo no escribo para ellos, yo escribo más bien para gente que viene de una historia más parecida a la mía (...) escribo para incomodar a quienes mantienen un discurso de los años setenta donde no hay grises. Prefiero ser molesta para los otros que alguien amigable para quienes defienden a agentes de la dictadura (Hilb, 31/10/2018).

El vocero de HNPP, por su parte, cada vez que se refirió a Hilb lo hizo por su nombre de pila, lo que denotaba cierta confianza o trato cercano entre ambos. Su admiración por la socióloga arraigó en su "honestidad intelectual" y en su capacidad para polemizar sobre discusiones que estarían presuntamente vedadas en la sociedad y en el campo académico. Las posiciones críticas de la autora sobre los actuales procesos judiciales en la búsqueda de la verdad fueron retomadas con ahínco por el vocero de HNPP, en tanto operación político-intelectual de apropiación:

¿No leíste Usos del pasado? En ese libro Claudia destruye todos los argumentos por los cuales la UBA les prohíbe estudiar. Desde distintos lugares, como distintas capas de argumento, ella los desarma todos (...) Una de las cosas que dice es que es muy peligroso permitirle a una institución, en este caso la academia, la universidad, ser guardiana de la moralidad, ${ }^{18}$ porque puede cambiar el tiempo político, cambian las autoridades... ¿qué pasa cuando hoy estoy de acuerdo con que prohíban a los militares estudiar y mañana sean los negros, los judíos, los blancos de ojos celestes? ¿Qué pasa cuando sea alguien con el que yo no esté de acuerdo? (Aníbal, 8/08/2015. El énfasis es nuestro).

La apelación literal a las ideas del libro nos ofrece un primer indicio del impacto que algunas lecturas tuvieron en él. Esto puede advertirse más claramente en la segunda dimensión que Aníbal recuperó del pensamiento de Hilb: su mirada filosófica sobre las virtudes de la Comisión para la Verdad y la Reconciliación en Sudáfrica. ${ }^{19 / 20}$ El vocero de HNPP, al igual que otros integrantes del grupo, afirmó que no se oponía al desarrollo de los juicios. Reconoció, por un lado, que el Juicio a las Juntas de 1985 había sido "absolutamente necesario", pero señaló, por el otro, que "la persecución penal conspira[ba] en algún aspecto contra la verdad y contra la resolución del conflicto definitiva” (Aníbal Guevara, 15/08/2015).

Para mí, cuando hablo de sanar, se sana desde la verdad, sin verdad no se sana. La justicia, en sí misma, no sana. ¿A mí de qué me sirve condenarte a vos si yo no sé qué pasó? Digo, ¿qué me va a traer más paz? ¿Hacerte mierda a vos o lograr saber la verdad? (Aníbal Guevara, 15/8/2015).

En términos más amplios, las lecturas e intercambios con intelectuales y académicos le aportaron a Aníbal -y a otros integrantes del colectivo de hijos y nietos- herramientas para abrir o generar interrogantes en el espacio público y privado. También les permitió repensar y reelaborar ciertos aspectos, como el nombre de la agrupación, e incorporar nuevos marcos teóricos en una coyuntura marcada por el ascenso de Cambiemos al poder y por la revitalización de las críticas hacia las políticas de DDHH del kirchnerismo. Estos intercambios y concepciones alternativas les aportaron una visión de futuro como un tiempo productivo de intervención. En esa clave, Aníbal afirmó sobre los juicios, en octubre de 2015, que "la situación general [estaba] llegando a un punto crítico que [iba] a forzar necesariamente un cambio de paradigma" (Aníbal Guevara, 13/10/2015).

A principios de 2016, la agrupación se conformó en asociación civil y sus integrantes eligieron llamarse Puentes para la Legalidad (PPL), un nombre que según su vocero reflejó con mayor fidelidad el espíritu del grupo. Algunas de las ideas emergentes que se promocionaron desde el ecléctico espacio dialógico pudieron advertirse en la nueva carta de presentación de PPL. Allí, el diálogo fue reafirmado como espíritu de grupo: 
Puentes para legalidad simboliza en toda su dimensión la oportunidad que tenemos de tender nuevos puentes que permitan superar las diferencias en la búsqueda de justicia a partir del encuentro, del diálogo. El puente como vínculo humano, como intercambio, simplemente ver al otro, reconocerlo y considerarlo (Carta de presentación de PPL, 2016. El énfasis es nuestro).

Esta posición le imprimió a algunos de los miembros del colectivo una disposición a construir vínculos con familiares e hijos de desaparecidos a partir de un común denominador que los aglutinó: el "dolor" por los efectos que aún padecen de la "tragedia de los setenta"; el "dolor" como un vaso comunicante de experiencias y realidades "no elegidas".

Luego de la publicación del libro Hijos de los setenta, de Arenes y Pikieln, se conocieron entre sí algunos hijos de militares acusados o condenados y de desaparecidos que habían formado parte de la trama allí narrada. Entre los hijos de desaparecidos que participaron en esta instancia se encontró el escritor Félix Bruzzone, autor de 76 y Los Topos, entre otros. También asistieron algunas hijas de militares y policías que en 2017 formaron el colectivo Historias Desobedientes, ${ }^{21}$ las escritoras del libro y Claudia Hilb (Analía Kalinec, 16/01/2019). Cuando el vocero de PPL caracterizó este espacio, se refirió a su flexibilidad: encuentros abiertos, indefinidos, pensados para juntarse a charlar y aunar "dolores".

Si bien en el espacio íntimo de la entrevista varios integrantes de PPL se refirieron a la necesidad de "salir del lugar de víctimas" en el que estaban anclados inicialmente - necesidad que concretaron con el abandono de la categoría de preso político- observamos una búsqueda constante por vincularse con "víctimas" o familiares de víctimas, en tanto figura social que predispone a la escucha y que necesita, además, del reconocimiento de los otros miembros de la comunidad de víctimas (Gatti, 2017). En este marco, la demostración de empatía - una condición necesaria para tener puentes con familiares de desaparecidos- emergió en varias entrevistas como una forma de comunicación verbal y no verbal aprehendida grupalmente (Macón, 2013). Fue en la articulación colectiva que varios integrantes de PPL incorporaron sensibilidades y sentimientos de compasión hacia el dolor de las víctimas del terrorismo de Estado y sus familiares, para luego traducirlos en códigos y formas de socialización. Ezequiel, un integrante de 32 años cuyo abuelo había estado procesado por crímenes de lesa humanidad cometidos en la provincia de Santiago del Estero, destacó justamente que la agrupación lo instaba a "ponerse en el lugar del otro":

Cuando llegué a Puentes [para la Legalidad] fue como una luz que se prendió, que estaba buscando (...). Yo creo que no me hubiese interesado sumarme a otra organización que tuviese otra mirada. Le comentaba esto a la hermana de Aníbal, no sé si la ubicás... yo le decía "nosotros tuvimos la suerte de entrar en esta organización que te retroalimenta el camino de entender al otro, de ponerte en el lugar del otro, de buscar qué podés estar haciendo mal vos, qué puede haber estado haciendo mal tu viejo o tu abuelo, y sin necesidad de caer en un bando, con la libertad de poder criticar todo y bueno, que salga algo bueno, positivo (Ezequiel, 11/03/2017. El énfasis es nuestro).

Esta orientación anclada en el "diálogo" fue ampliando los márgenes de intervención pública y privada, pero desató a nivel interno una serie de discusiones internas referidas al carácter y la jerarquía de los objetivos grupales. Para Milena -quien tuvo un rol clave en la estructuración del colectivo hasta que lo abandonó a fines de 2017-, militar las consignas alternativas de diálogo o reconciliación resultaba contradictorio con el objetivo fundante del colectivo, que había sido desde el inicio bregar por la legalidad de los procesos judiciales, aceptando de antemano que estos se realizaran. En cambio, en la mirada de Romina, una integrante de 28 años que se incorporó en 2015, las nociones de "diálogo" y "encuentro" constituyen elementos inherentes de la identidad de PPL, que en su nueva carta de presentación del 2016 incluyó esos valores (Romina, 6/02/2019). Estas diferencias dan cuenta de un formato inacabado y en elaboración constante, con diferencias internas entre sus miembros, quienes pugnan por definir qué es o debería ser el colectivo, sobre la base de distintas concepciones, conocimientos, aprendizajes y evaluaciones hechas del escenario coyuntural.

A nivel externo, la incorporación de visiones dialoguistas provocó el rechazo visceral de algunos familiares y miembros de otras agrupaciones que defendían a militares, policías y civiles procesados o condenados por crímenes de lesa humanidad. El 9 de marzo de 2017 los integrantes publicaron en su página de Facebook un álbum con fotos y frases de Claudia Hilb, Graciela Fernández Meijide, Elisa Carrió (diputada de 
Cambiemos), Luján Bertella (ex detenida desaparecida) y Norma Morandini, como un modo de rendir homenaje a "mujeres que tienden puentes". La apelación a figuras y voces distintas de las "víctimas de la subversión” motivó una serie de comentarios negativos por parte de familiares de militares no nucleados en la agrupación, para quienes tales inclusiones resultaron inadmisibles:

No sería mejor honrar a las esposas, hijas, nietas, madres de nuestros familiares? [sic] No es más [sic] representativa una Maby Picón o una Victoria Villarruel que son mujeres que se juegan por los nuestros? No hay necesidad de querer quedar bien con quienes nos ningunean (Comentario de Mercedes Soto Escudero, Facebook, 9/03/2017).

Es TRAICIÓN, si, así, con mayúsculas, la más abyecta de las traiciones porque es la del cobarde, la del carente de honor, la del gusano que nace de la podredumbre y muere en ella. Los conozco bien a todos y cada uno de ellos (Comentario de Raúl R Moleón, Facebook, 10/03/2017. Las mayúsculas son originales).

Las referencias que aparecieron en estos comentarios a "los nuestros", "nuestro lado" y la acusación de "traición" pusieron de manifiesto un nosotros que los integrantes de la otrora HNPP y hoy PPL debieron tensar, no sin conflictos ni resistencias. Los "puentes" que buscaron tender, a partir de la recepción de lecturas y articulación con agentes intelectuales, políticos y productores de ideas no obedecieron meramente a una estilización del discurso. Como nos muestra el relato de Ezequiel, también implicaron un acto performativo sobre sus propias identidades en un contexto más amplio, signado por el florecimiento de redes, sociabilidades y vínculos con actores diversos, que los predispuso a actuar e intervenir públicamente de una manera cercana a la producción de contenidos "dialógicos".

\section{Conclusiones}

En este artículo encaramos algunos de los debates, cuestionamientos y críticas hacia las políticas de DDHH implementadas durante el kirchnerismo, las cuales resurgieron y cobraron notoriedad a partir de la coyuntura clave que visibilizó un conflicto político, económico, cultural y social luego de las discusiones de 2008. El elemento novedoso de este "revival crítico", que más adelante dio cauce a la configuración de redes y espacios de ideas anclados en la noción de diálogo, pudo advertirse en los perfiles y trayectorias de los sujetos de enunciación: se trata de actores que producen visiones alternativas del pasado reciente desde posiciones privilegiadas en el campo cultural, intelectual, académico, político y de los DDHH y que, como tales, poseen credenciales de distinto tipo que habilitan y jerarquizan su palabra en el espacio público.

El énfasis que hicimos en la categoría diálogo permitió nominar esta red de espacios y actores con relaciones menos o más consolidadas, que apelaron a esta categoría para contraponerla a un estilo caracterizado como "cerrado", "parcial" y "obtuso" respecto del tratamiento de la "tragedia" de los setenta, atribuido al kirchnerismo por estos agentes. Estas visiones, que se presentan como "plurales", “abiertas" y seculares, se materializaron en productos culturales y políticos con amplia circulación en ámbitos diversos.

La reposición del 2008 como una coyuntura clave implicó además la asunción de otra premisa: la existencia de lazos y recorridos de memoria que trascendían o corroían las fronteras formales entre gobiernos. En este sentido, consideramos necesario incorporar, por un lado, otras, temporalidades y dinámicas del conflicto social más generales, que afectan el pulso de las memorias, y atender, por el otro, las intersecciones que se producen entre actores y espacios diversos, incluyendo al Estado, pero sin agotar la mirada en sus instituciones. Esta perspectiva no implica desconocer la centralidad del actor estatal: vimos en el primer apartado que la posición de Pablo Avelluto resultó fundamental en tanto intermediario cultural, difusor y productor, así como articulador de personajes clave en esta nueva matriz dialógica, como Iván Petrella, Graciela Fernández Meijide, Héctor Leis y miembros del Club Político, entre otros. Los frutos de la función de Avelluto no se vieron solo en el espacio de la industria cultural sino también en el plano político, como refleja su tarea llevada adelante desde la posición estratégica del área de Cultura de la Nación.

Por último, el breve análisis del repertorio de acción colectiva de la agrupación Puentes para la Legalidad nos permitió dimensionar el alcance que tuvo la recepción de este cuerpo de ideas emergentes en un espacio 
de militancia concreto. Para ello, resultó imperioso abandonar la mirada normativa y homogénea que suele primar en el estudio de las agrupaciones que bregan por los intereses de militares, policías y civiles condenados por crímenes de lesa humanidad, para adoptar un enfoque que nos permitiera advertir la especificidad de este colectivo: los lazos que construyeron, las estrategias e intereses que sostienen sus repertorios de acción y el modo en que estos aspectos se anudan y devienen en valores y emociones. Ciertamente, la valoración que los integrantes de este colectivo hicieron de los intercambios con intelectuales, académicos, políticos y gestores culturales que promueven la categoría de diálogo develó lecturas activas, pero también redes, vínculos y sensibilidades -compartidas entre diferentes actores y esferas- que desafían los marcos teóricos y analíticos disponibles para analizar los conflictos por la memoria del pasado reciente.

\section{BiBLIOGRAFÍA}

Arenes, C., y Pikielny, A. (2016). Hijos de los setenta. Historias de la generación que heredó la tragedia argentina. Buenos Aires: Sudamericana.

Bertoia, L. (2016). La agenda de memoria, verdad y justicia en tiempos de cambios. Aletheia, 7(13),1-18. Recuperado a partir de http://hdl.handle.net/10915/57815

Bonnin, J. E. (2015). Los discursos sobre la reconciliación. Variaciones en torno al perdón, la verdad y la justicia. En C. Feld y M. Franco, (comp.), Democracia, hora cero. Actores, politicas y debates en los inicios de la posdictadura (225-268). Buenos Aires: FCE.

Carnovale, V. (2015). Instantáneas: Los juicios al Mal. Verdad, Justicia y Derechos Humanos en Argentina. Politicas de la Memoria, 16, 5-13.

Fioravanti, E. (2018). "La tragedia de los setenta". Un estudio etnográfico sobre el activismo de familiares de militares Juzgados por delitos de Lesa Humanidad. Buenos Aires: IDAES. UNSAM.

Galak, O. (2006). Controversia por el prólogo agregado al informe "Nunca más". La Nación, 23/05/2011, Recuperado a partir de https://www.lanacion.com.ar/politica/controversia-por-el-prologo-agregado-al-informe-nunca-mas -nid807208

Goldentul, A. (2018). Surgimiento y transformaciones de la agrupación Hijos y Nietos de Presos Políticos en Argentina. Aposta, 76, 140-164.

Goldentul, A., y Saferstein, E. (2018). La conformación de una nueva comunidad "dialógica" en torno a la memoria del pasado reciente en Argentina (2008-2017). Presentado en XI Seminario Internacional Políticas de la Memoria, Buenos Aires.

Hilb, C. (2013). Usos del pasado: qué hacemos hoy con los setenta. Buenos Aires: Siglo XXI.

Hilb, C. (2014). Justicia, reconciliación, perdón. Cómo fundar una comunidad después del crimen. En Lesa humanidad. Argentina y Sudáfrica: reflexiones después del Mal (53-74). Buenos Aires: Katz.

Macón, C (2013). "Sentimus ergo sumus: el surgimiento del "giro afectivo" y su impacto sobre la filosofía política". Revista Latinoamericana de Filosofia Politica, V. II, 6 (2), 1-32.

Montero, A. S. (2016). El objeto discursivo "dictadura cívico-militar" en la Argentina reciente: narrativas históricas y sentidos contemporáneos. Crítica Contemporánea, Revista de Teoria Politica, 6, 53-77.

Mouffe, C. (2012). La paradoja democrática. El peligro del consenso en la política contemporánea. Barcelona: Gedisa.

Oberti, A., y Pittaluga, R. (2016). Apuntes para una discusión sobre la memoria y la política de los años 60/70 a partir de algunas intervenciones recientes. Sociohistórica, 38, e015, 1-22.

Petrella, I. (2015). Que se metan todos: el desafí de cambiar la política argentina. Buenos Aires: Sudamericana.

Salazar, P. J. (2014). La reconciliación como modo de vida ética de la república. En Lesa humanidad. Argentina y Sudáfrica: reflexiones después del Mal. Buenos Aires: Katz.

Salvi, V. (2012). De vencedores a víctimas. Memorias militares sobre el pasado reciente en la Argentina. Biblos: Buenos Aires. 
Saferstein, E. (2016). La década publicada. Los best sellers politicos y sus editores: producción de libros, difusión de temas e intervención pública en el mercado editorial argentino (2003-2015) (Tesis de Doctorado). Facultad de Ciencias Sociales - Universidad de Buenos Aires, Buenos Aires, Argentina.

Saferstein, E. (2017). La edición como intervención cultural, comercial y política: best-sellers políticos del director de Random House-Sudamericana en el kirchnerismo. Millcayac - Revista Digital de Ciencias Sociales, 4(7), 141-164.

Saferstein, E., y Goldentul, A. (2019, en prensa). El "diálogo" como discurso emergente: la articulación de un espacio de ideas en torno a la memoria del pasado reciente en Argentina (2008-2018). Políticas de la Memoria, 19.

Tarcus, H. (2013). Marx en Argentina. Buenos Aires: Siglo XXI.

Torras, V. (10 de septiembre de 2015). La delgada línea amarilla. Revista Haroldo, s/p. Recuperado a partir de http:/ /www.revistaharoldo.com.ar/nota.php?id=34

Torras, V., y Bertoia, L. (2017). Memorias en disputa. Un análisis del discurso público. Ponencia presentada en $X$ Seminario Internacional Politicas de la Memoria. Buenos Aires, Argentina.

Vezzetti, H. (2014). Verdad jurídica y verdad histórica. Condiciones, usos y límites de la figura del "genocidio". En C. Hilb, P. J. Salazar y L. Martín (editores), Lesa humanidad. Argentin a y Sudáfrica: reflexiones después del Mal (pp. 17-37). Buenos Aires: Katz.

Vicente, M. (2015). De la refundación al ocaso. Los intelectuales liberal-conservadores ante la última dictadura. La Plata: FaHCE/UNGS.

Vommaro, G. (2017). La larga marcha de Cambiemos: la construcción silenciosa de un proyecto de poder. Buenos Aires: Siglo XXI.

Vommaro, G. (2017). La centroderecha y el «cambio cultural» argentino. Nueva Sociedad | Democracia y politica en América Latina, 270, 4-13.

\section{REFERENCIAS}

Avelluto, P. (2013, junio 25). Elogio del diálogo. La Nación. Recuperado a partir de https://www.lanacion.com.ar/1 595134-elogio-del-dialogo

Palermo, V. (2016, Junio 1). En el Club Político Argentino somos amigos del Gobierno y como a todo amigo, lo bancamos. Recuperado a partir de https://www.infobae.com/2016/06/01/1815583-en-el-club-politico-argent ino-somos-amigos-del-gobierno-y-como-todo-amigo-lo-bancamos/

\section{Notas}

1 Oberti y Pittaluga (2016) realizan una crítica a la noción de "memoria oficial" con la que algunos autores se refirieron a las políticas de memoria impulsadas por el kirchnerismo. Según los autores, estas lecturas partirían de la premisa de un relato monolítico, único, compacto y homogéneo, que fue adoptado e impulsado por el Estado, haciendo caso omiso de una supuesta heterogeneidad de actores, posturas, estrategias y enfoques que participan en la construcción de sentidos sobre el pasado reciente. Si bien es posible identificar diversos espacios que conviven dentro del otrora oficialismo en torno a estos temas, es evidente la construcción de una hegemonía discursiva en torno al pasado reciente por parte del Estado. Esta es identificable en el prólogo al Nunca Más de 2006, firmado por la Secretaría de Derechos Humanos, dirigida en ese momento por Eduardo Luis Duhalde. En contraposición al prólogo original, que de alguna manera fundaba la "teoría de los dos demonios", el prólogo de 2006 oficializaba la no equiparación entre las acciones cometidas desde el Estado dictatorial y las cometidas por las organizaciones armadas. Según Duhalde, el nuevo prólogo expresaba "los lineamientos de la política pública fijada por el Presidente de la Nación en este tema" (Galak, 2006), lo que posicionaba una visión en detrimento de otras por parte del Estado.

2 Si bien algunos de estos autores venían publicando desde la década del noventa miradas críticas de la experiencia armada en Argentina, consideramos que a partir del 2003, y más intensamente luego 2008, se modificaron las condiciones de circulación y recepción de sus obras, lo que permitió interpelar a actores que se ubicaban por fuera del campo académico y de la militancia.

3 El Club Político es un colectivo creado en junio de 2008 en el contexto del conflicto agrario. Desde su conformación nuclea a intelectuales, periodistas y académicos que se opusieron al entonces gobierno En esa misma coyuntura se crearon 
distintos colectivos de intelectuales y académicos, como Carta Abierta, creado en 2008 por intelectuales y artistas afines al kirchnerismo, y Plataforma 2012, constituido ese año por académicos e intelectuales de izquierda, también críticos del gobierno. En contraste con el predominio de perfiles académicos en Plataforma 2012, el CPA tuvo una composición más ecléctica, que albergó a políticos, editores, escritores y ensayistas. En junio de 2016, en el marco de una entrevista concedida al portal Infobae, y en relación al gobierno de Cambiemos, el presidente del CPA Vicente Palermo afirmó que la posición del colectivo era de un "acompañamiento constructivo" ["no somos parte del Gobierno, pero hacemos un acompañamiento constructivo”] (Infobae, 1/06/2016)

4 En palabras del autor: "La verdad es muy compleja, los papeles no son fáciles de distinguir. Pero todos se ven las caras, todos hablan (...) Hay que facilitar el cara a cara. Hace falta liberar la palabra, el diálogo y el encuentro con el otro, que es la base de la democracia" (Petrella, 2016, p. 155).

5 Desde la transición democrática (1982-1983) podemos rastrear su uso por parte de diversos actores eclesiásticos y políticos (Bonnin, 2015), en discursos de agrupaciones de civiles y militares retirados que surgieron en la etapa democrática para hacer una defensa ideológica de lo actuado en dictadura y de sus agentes (Salvi, 2012). También se puede ver en medios de comunicación que durante la década del noventa coadyuvaron a un "encuentro" entre "las partes” (Feld, 2001). Generalmente, la categoría era utilizaba de manera indistinta junto con la idea de reconciliación, o bien se la entendía como un estadio previo y necesario que decantaría posteriormente en el arrepentimiento y perdón mutuos.

6 Estas operaciones de resignificación encuentran matices en los autores revisitados: Meijide milita abiertamente la noción de "diálogo" y se opone a instrumentar el "perdón” como política de Estado, mientras que Hilb conserva en sus escritos la categoría de reconciliación, aunque apelando a ella con un sentido estrictamente político, no religioso, cuando examina los efectos positivos que puede tener la implementación de este dispositivo en la rehumanización de las víctimas y de los victimarios, y en la construcción de una escena de interés común en el espacio público (Hilb, 2013; 2014).

7 Esto puede leerse en sintonía con la conformación nacional de una "nueva derecha", que, a diferencia de anteriores experiencias liberal-conservadoras (Vicente, 2015), se despega del discurso católico (Morresi y Vommaro, 2015).

8 Orientados a presentar los testimonios de distintas personalidades internacionales que fueron protagonistas de procesos de diálogo intercultural y de reconciliación "postconflicto", en octubre de 2016 el Ministerio de Cultura lanzó el programa Diálogos Globales, que constó de una serie de encuentros de discusión moderados por personalidades locales que pueden ser encasilladas dentro de la referida matriz dialógica de los derechos humanos. El encuentro referido aquí fue moderado por Norma Morandini. Disertaron representantes de países que atravesaron procesos de conflicto y posterior reconciliación, como Sudáfrica luego del apartheid, Colombia con las FARC, Canadá con los pueblos indígenas, y los países árabes con el conflicto con el Estado Islámico, entre otros (Goldentul y Saferstein, 2018).

9 El evento IDEAS. Pensemos juntos el futuro se desarrolló en tres días, 22, 23 y 24 de septiembre de 2017 en el Centro Cultural de la Ciencia. Uno de los ejes estuvo enfocado en "Memoria y futuro". Entre los invitados se encontraban el intelectual mediático francés Bernard-Henri Lévy, el ensayista norteamericano David Rieff y el representante de la Comisión de Verdad y Reconciliación de Sudáfrica Charles Villa-Vicencio, que también había dado su presente en Diálogos Globales (Goldentul y Saferstein, 2018).

10 Entre los portales de noticias que se hicieron eco del hecho, se encuentran La Nación, Infobae, Clarín, Perfil, La Razón, El Argentino, Página 12, El Periódico, La Voz Noticias, TN, Urgente 24 y Site Corte Suprema.

11 Con excepción del vocero de Puentes para la Legalidad, Aníbal Guevara, a quien nos referimos por su nombre real (a veces como Aníbal y otras veces como Guevara o Aníbal Guevara), para el resto de los entrevistados utilizamos seudónimos a fin de preservar sus identidades.

12 Entre varias anécdotas, Aníbal describió la vez que, junto a otros hijos, visitó a Luciano Benjamín Menéndez en su casa de Córdoba y allí el exgeneral les planteó la necesidad de ampliar los objetivos de la agrupación: además de denunciar “irregularidades" en los juicios debían pronunciarse a favor de una "guerra” que había sido "justa” (Aníbal Guevara, $15 / 10 / 2015)$.

13 Como la mayoría de las agrupaciones que denuncian "irregularidades" en los procesos judiciales y de detención, los integrantes de Puentes para la Legalidad alegan que los derechos de sus familiares son violados. En primer lugar, por haber sido condenados por crímenes que no estaban previstos en el código penal en el momento de los hechos (violación del principio de retroactividad de la ley) (Sanjurjo, 2016). En segundo lugar, cuestionan a dos actores centrales del ritual judicial: los jueces y los testigos. Los primeros son descalificados por su viciosa interpretación de las normas y por su falta de imparcialidad; mientras que los segundos son acusados de prestar declaraciones poco veraces, no necesariamente por una deliberada intención de mentir sino por la textura viscosa, tramposa o volátil que le adjudican a las memorias. Como tercer punto, señalan que las demoras en los procesos judiciales sedimentan en condiciones de detención que contradicen lo pautado en el derecho, debido a la vejez o a la expiración de la fecha de prisión preventiva. Organismos de DDHH como el CELS y algunas unidades estatales especializadas en la temática han reconocido demoras en los procesos judiciales, aunque también advierten que ello forma parte de una tendencia estructural mayor del sistema penal argentino. Los integrantes de PPL señalan, como contrapartida, que estas "tendencias generales" se agravan en la 
población de lesa humanidad, si comparamos su situación (donde hay sobrerrepresentación de detenidos mayores de 70 años) con la del segmento de adultos mayores detenidos por delitos comunes (no así con la población total de detenidos). De acuerdo al último informe de la Procuraduría de Crímenes de Lesa Humanidad, "el análisis de las trayectorias temporales muestra que insume un promedio de cinco años que una causa se eleve, se realice el juicio, y se confirme o no la sentencia en las instancias recursivas posteriores. Aun suponiendo que en las más de 200 causas en instrucción se presente el requerimiento de elevación en 2019, como mínimo, la finalización del proceso demoraría hasta mediados de 2025” (Informe Estadístico de la Procuraduría de Crímenes de Lesa Humanidad, 27/12/2018).

14 Sobre este punto, es necesario subrayar que las redes interpersonales que se fueron hilvanando entre miembros de la agrupación y algunos funcionarios o referentes de PRO/Cambiemos, académicos e intelectuales, no pueden ser reducidos a la mera construcción de vínculos que apuntaron a la obtención de beneficios sobre la condición legal de sus familiares. Queremos enfatizar, en cambio, ciertas visiones, sensibilidades e inquietudes compartidas, que forman parte de una recepción que los habilitó a participar de libros, reuniones, seminarios y eventos, sin que ello les remitiera necesariamente resultados concretos, visibles o inmediatos.

15 En el estreno estuvieron presentes Hernán Lombardi (ex ministro de Cultura porteño y titular del Sistema Federal de Medios y Contenidos Públicos de la República Argentina desde 2015), Gabriela Michetti (ex senadora del PRO y vicepresidenta de la Nación desde 2015), Laura Alonso (ex diputada del PRO y titular de la Oficina Anticorrupción), Juan Carlos Strassera (ex fiscal en el Juicio a las Juntas), María Matilde Ollier (doctora en Ciencia Política y profesora universitaria de renombre) y Ernesto Sanz (ex senador de la UCR y principal articulador del acercamiento de la UCR al PRO en la alianza Cambiemos) y Jaime Durán Barba (asesor político de Mauricio Macri desde que este ocupara el cargo de jefe de Gobierno de la Ciudad de Buenos Aires en 2007).

16 Las Fuerzas Armadas de Liberación (FAL) fueron una organización guerrillera de ideología marxista-leninista que tiene sus orígenes aproximadamente en 1963 en Argentina, que utilizó también el nombre de Fuerzas Argentinas de Liberación.

17 En su último libro, Hilb dedicó unos párrafos al libro Hijos de los setenta y destacó el vínculo que establecieron Aníbal Guevara y Félix Bruzzone, señalando que se trata de dos hombres "jóvenes", "de la misma edad", "íntegras" y "respetables" (Hilb, 2018, p. 153).

18 El 8 de agosto de 2012 el Consejo Superior de la UBA aprobó por unanimidad rechazar la admisión de estudiantes imputados o condenados por crímenes de lesa humanidad al Programa UBA XXII, que se imparte en las cárceles. A raíz de esta resolución, Hilb incluyó en su libro unas páginas dedicadas a cuestionar la posición que asumió la UBA, en tanto se establecieron condiciones de "admisibilidad moral” sobre sus estudiantes. Allí señaló como un error de la resolución el no distinguir entre procesados y condenados, negándoles a los primeros el "principio de inocencia”.

19 En la mirada de la autora, la solución sudafricana instituyó una "comunidad de interés" entre víctimas y victimarios: mientras las primeras narraron los abusos sufridos y pudieron solicitar una reparación económica, los segundos debieron exponer sus crímenes ante la comisión y, en caso de fundamentar que el móvil que los llevó a cometer el delito había político, pudieron pedir una amnistía. Este dispositivo sedimentó, según Hilb, en un hecho tan particular como sugerente: los perpetradores fueron "los más interesados" en decir la verdad.

20 Para una mirada crítica de la labor de la Comisión para la Verdad y la Reconciliación, véase Pineau y Flores (2016).

21 Historias Desobedientes surgió en mayo de 2017, luego de la decisión de la Corte Suprema de Justicia de la Nación de aplicar la Ley 2 x 1 (https://es.wikipedia.org/wiki/Dos_por_uno_en_cr\%C3\%ADmenes_de_lesa_humanidad) y en el marco de las movilizaciones sociales convocadas por los organismos de derechos humanos en contra de su aplicación. Desde entonces, la agrupación abraza las consignas históricas de memoria, verdad y justicia, reivindica la lucha de los organismos de DDHH y condena abiertamente los crímenes cometidos por sus familiares, a quienes califican de "genocidas". Con el objetivo de "romper con los mandatos de silencio", en noviembre de 2017 los integrantes del colectivo presentaron en el Congreso un proyecto de ley de reforma del Código Procesal Penal para que la Justicia los habilite a denunciar y declarar en los juicios contra sus familiares. 